\title{
Editorial: modern trends in landslide mechanics
}

Landslides are a major hazard and therefore actively studied in various disciplines, from sociology, urban planning and crisis management to geodesy, geology and geophysics. Each discipline uses its own research tools. For geotechnical engineers, it is mechanics that facilitates understanding landslide mechanisms, predicting landslide behaviour and designing mitigation measures. Also, from a soil-mechanics perspective, landslides constitute enormous, full-scale field experiments that can serve to validate a broad range of mechanical models, from the constitutive models of elementary soil behaviour to numerical and analytical methods for solving the inverse coupled boundary-value problems of continuum and fracture mechanics. Once validated, these models and methods can be applied to other geotechnical problems.

Over the past decade, several groups in geotechnical engineering and the earth sciences have made substantial and innovative advances in the mechanical analysis and simulation of landslides. Their work, however, has been scattered across a number of different journals, addressing sometimes non-overlapping audiences. The present themed issue of Géotechnique aims to provide a common venue for a series of invited papers focused on the latest developments in geotechnical engineering and the earth sciences related to landslide mechanics. Six high-quality contributions cover a wide range of problems and approaches - from slow creeping to rapid catastrophic landslides, from unsaturated subaerial to fully saturated submarine slopes, from shear-band-propagation mechanisms of landslide-failure initiation to mass-transport dynamics of the post-failure phase.

The first three papers of this issue are concerned with the transition from slow to rapid landslide motions. Iverson and George (2016) explore the mechanisms distinguishing between landslides that move slowly or with intermittent velocity downslope and those that liquefy during the early stages of motion, leading to runaway acceleration and high-speed runout across low-relief terrain. They propose a two-phase, depth-integrated landslide-dynamics model that combines principles from soil mechanics, granular mechanics and fluid mechanics. As an illustration, they study the dynamics of a disastrous landslide that occurred near Oso, Washington, USA, on 22 March 2014. Puzrin et al. (2016) summarise recent developments in the application of the shear-band-propagation approach to submarine landslide evolution, focusing on transitions between progressive (stable) and catastrophic (unstable) types of slope failure. Within this approach various geomorphological features, such as slab failures, spreadings, ploughings and runouts are described in a simple unified framework. The simple form of the resulting criteria makes it possible to incorporate them into geographic information systems (GIS)-based deterministic and probabilistic slope-stability analyses of offshore developments, explaining the enormous dimensions of observed palaeo-landslides and their historical frequencies. Alonso et al. (2016) describe the transition from creeping motions to a rapid event as well, but they focus on thermo-mechanical interactions at the scale of the sliding surface as a critical aspect for explaining these motion phases and the relationship between them. The proposed models can be used to back-analyse relevant case histories and also, in principle, to carry out predictive modelling, provided that an adequate calibration is available for the material parameters.
The subsequent two papers focus on the environmentally driven evolution of subaerial landslides. Laloui et al. (2016) present a continuum-modelling approach for the analysis of wetting-induced instability phenomena at the onset of failure in loose volcanic ash slopes. They carried out a numerical simulation of a landslide-prone volcanic slope in Costa Rica, using a two-dimensional coupled hydro-mechanical finiteelement slope model that is based on the effective-stress concept and has been extended to partially saturated conditions. Their results underline the importance of slope geometry and wetting-drying cycles for the evolution of matric suction and wetting-induced deformation and for the development of a localised-shear-failure mechanism in unsaturated conditions. Oberender and Puzrin (2016) propose a simplified observation-guided constitutive modelling (OGCM) approach to the analysis of the evolution of creeping landslides. Their approach treats a landslide as a series of macro elements, where suitable adaptable constitutive models and their parameters can be derived from displacement and pore-water-pressure measurements. When applied to the St Moritz-Brattas landslide in Switzerland, the calibrated landslide models successfully describe the complex behaviour of all three distinctive regions of the landslide.

The last paper of this issue, by Soga et al. (2016), is a comprehensive discussion of various methods for largedeformation analysis and their applicability for solving landslide problems. They introduce two approaches to model soil-pore-fluid coupling in large-deformation analysis using the material point method (MPM) and present example simulations for each of them: one on a model levee failure and the other on a natural cut-slope failure (the Selborne experiment). In the levee-failure case, the MPM simulation captures the development of successive shear bands during failure propagation and the subsequent consolidation stage. In the Selborne case, the MPM simulation successfully modelled the progressive failure of the brittle overconsolidated clay.

The editorial sub-panel for this themed issue consisted of Mark Randolph, Vaughan Griffiths, William Murphy, Rocco Lagioia, Eduardo Alonso, Manuel Pastor, Lyesse Laloui, James Rice and myself, and we are all grateful for the prompt responses we received from our reviewers and authors, which made it possible to bring this themed issue from first manuscript submission to printed copy in 12 months. Due to its limited size the issue could not include contributions from all the research groups working on landslide mechanics, but we hope that Géotechnique will provide ample opportunities in the future to publish their excellent work.

\section{Alexander M. Puzrin} ETH Zurich

\section{REFERENCES}

Alonso, E. E., Zervos, A. \& Pinyol, N. M. (2016) Thermoporo-mechanical analysis of landslides: from creeping behaviour to catastrophic failure. Géotechnique 66, No. 3, 202-219, http:// dx.doi.org/10.1680/jgeot.15.LM.006.

Iverson, R. M. \& George, D. L. (2016) Modelling landslide liquefaction, mobility bifurcation and the dynamics of the 2014 Oso disaster. Géotechnique 66, No. 3, 175-187, http:/l dx.doi.org/10.1680/jgeot.15.LM.004.

Laloui, L., Ferrari, A., Li, C. \& Eichenberger, J. (2016) Hydro-mechanical analysis of volcanic ash slopes during 
rainfall. Géotechnique 66, No. 3, 220-231, http://dx.doi.org/ 10.1680/jgeot.15.LM.001.

Oberender, P. W. \& Puzrin, A. M. (2016) Observation-guided constitutive modelling for creeping landslides. Géotechnique 66, No. 3, 232-247, http://dx.doi.org/10.1680/jgeot.15.LM.003.

Puzrin, A. M., Germanovich, L. N. \& Friedli, B. (2016) Shear band propagation analysis of submarine slope stability.
Géotechnique 66, No. 3, 188-201, http://dx.doi.org/10.1680/ jgeot.15.LM.002.

Soga, K., Alonso, E., Yerro, A., Kumar, K. \& Bandara, S. (2016) Trends in large-deformation analysis of landslide mass movements with particular emphasis on the material point method. Géotechnique 66, No. 3, 248-273, http://dx.doi.org/10.1680/ jgeot.15.LM.005. 